\title{
The impact of secondary hyperparathyroidism on the efficacy of antiresorptive therapy
}

\author{
Gyöngyvér Kincse ${ }^{1}$, József Varga ${ }^{2}$, Péter Somogyi ${ }^{3}$, Péter Szodoray ${ }^{4}$, Péter Surányi ${ }^{1}$ and János Gaál ${ }^{* *}$
}

\begin{abstract}
Background: The aim of the present study was to assess whether the efficacy of bisphosphonate treatment is influenced by PTH levels measured in newly diagnosed osteoporotic patients and to identify the threshold value, beyond which PTH level negatively influences therapeutic efficacy.

Methods: One hundred and thirty-eight osteoporotic patients were enrolled into the study. All subjects underwent laboratory screening, bone densitometry with DEXA, and x-ray imaging. The changes in bone density were evaluated after a mean follow-up period of $13.37 \pm 1.29$ months. Correlation analysis was performed on the clinical data of patients, the percentage changes of BMD values, and the PTH levels measured at the beginning of study, using SPSS software.

Results: The mean age of the subjects was $64.82 \pm 10.51$ years, and the female-to-male ratio was $116 / 22$. Baseline BMD value measured with AP DEXA scanning was $0.854 \pm 0.108 \mathrm{~g} / \mathrm{cm}^{2}$ in the $L_{1-4}$ vertebrae and $0.768 \pm 0.115 \mathrm{~g} / \mathrm{cm}^{2}$ in the left femoral neck. By the end of the follow-up period, these values changed to $0.890 \pm 0.111 \mathrm{~g} / \mathrm{cm}^{2}$ and $0.773 \pm 0.111 \mathrm{~g} / \mathrm{cm}^{2}$, respectively. We found a statistically significant, negative correlation between PTH levels and the percentage changes of lumbar BMD values measured at the end of the follow-up (correlation coefficient $R^{2}=0.121, p<0.0001$ ). The analysis of frequency histograms suggested that negative effects on bone might be expected above a PTH level of $60 \mathrm{pg} / \mathrm{mL}(7.3 \mathrm{pmol} / \mathrm{L})$.
\end{abstract}

Conclusion: Our findings imply that a baseline PTH level over $60 \mathrm{ng} / \mathrm{mL}$ can reduce the efficacy of bisphosphonate treatment.

Keywords: D vitamin status, PTH level, Antiresorptive therapy, Efficacy

\section{Background}

Osteoporosis is considered a public health problem in an increasing number of countries. According to the initial results of the epidemiological studies conducted in Hungary during the mid-90's, primarily in international co-operation, the nationwide prevalence of osteoporosis in the population over 50 years of age was $32.3 \%$ among women and $23.6 \%$ among men [1]. This means that osteoporosis afflicts approximately 600,000 women and more than 300,000 men overall in Hungary [2].

Anti-resorptive agents, including oral or parenteral aminobisphosphonates (e.g. alendronate, risedronate, ibandronate, and zolendronate), with a mechanism of action based on the blockade of mevalonate metabolism,

\footnotetext{
* Correspondence: gaalja@freemail.hu

'Department of Rheumatology, 'Kenézy Gyula' Hospital, Bartók Béla út 2-26, H- 4032, Debrecen, Hungary

Full list of author information is available at the end of the article
}

play an outstanding role in the management of osteoporosis. These agents inhibit the isoprenylation of small GTPases, which are signalling proteins important in the maintenance of cell structure [3].

Calcium and vitamin D sufficiency is a prerequisite to effective antiresorptive therapy, especially in the elderly population [4]. Low vitamin $\mathrm{D}_{3}$ level triggers the compensatory release of parathormone (PTH) [5], which increases the risk of fractures [6], as well as interference with neuromuscular function $[7,8]$. Vitamin D sufficiency, as well as optimal levels of activated vitamin $\mathrm{D}_{3}$ (1,25-dihydroxy-vitamin D) can suppress PTH secretion [9]. Above-normal PTH levels were detected in $17.4 \%$ of postmenopausal women treated for osteoporosis [10], and a negative correlation was found between PTH and vitamin D levels [11]. When 25(OH)-vitamin D level
Ciomed Central

(c) 2012 Kincse et al.; licensee BioMed Central Ltd. This is an Open Access article distributed under the terms of the Creative Commons Attribution License (http://creativecommons.org/licenses/by/2.0), which permits unrestricted use, distribution, and reproduction in any medium, provided the original work is properly cited. 
decreases below $4.6 \mathrm{ng} / \mathrm{mL}$, serum PTH level reaches the upper limit of the normal range $(65 \mathrm{pg} / \mathrm{mL})$ [12].

There were some important premises that have prompted us to conduct this study. According to the Bhattoa et al., serum $25(\mathrm{OH})$-vitamin $\mathrm{D}_{3}$ is below normal in $56.7 \%$ of postmenopausal women in Hungary [13], and a significant portion of these patients expectedly have higher than normal PTH levels. Unfortunately, bone loss continues despite adequate bisphosphonate therapy and supplementation with calcium and vitamin $\mathrm{D}_{3}$ in 8 to $23 \%$ of osteoporotic patients (bisphosphonate resistance) [14], and several publications have suggested a role for secondary hyperparathyroidism in the aetiology of bisphosphonate resistance $[15,16]$.

The aim of the present study was to assess the prevalence of secondary hyperparathyroidism (vitamin $\mathrm{D}_{3}$ deficiency) among newly diagnosed osteoporotic patients and to evaluate whether baseline levels of PTH influence the efficacy of anti-osteoporotic treatment (with bisphosphonates) in this population. Furthermore, we determined the threshold, beyond which PTH level has a negative impact on the efficacy of bisphosphonate treatment.

\section{Methods}

\section{Type of study}

This study was a prospective, observational, noninterventional study.

\section{Inclusion and exclusion criteria}

Patients meeting the following criteria were eligible for inclusion: $i$ ) diagnosed idiopathic osteoporosis with a lumbar and/or femoral T-score lower than -2.5; ii) patients newly identified and enrolled to follow-up; iii) patients with laboratory findings available.

The exclusion criteria were as follows: $i$ ) diagnosed secondary osteoporosis; ii) history of a malignancy; iii) renal failure (GFR $<65 \mathrm{~mL} / \mathrm{min}$ according to the Cockroft-Gault formula); iv) severe liver disease; $v$ ) hypo-/hyperthyroidism; vi) malabsorption syndrome; vii) hypercalcaemia; viii) hypocalcaemia; $i x$ ) history of renal calculosis; $x$ ) previous anti-osteoporotic therapy with bisphosphonates, selective estrogen-receptor modulators (SERMs), strontium ranelate, teriparatide, or calcitonin.

\section{Study population}

Two hundred and thirty-two patients met the inclusion criteria, and data from 138 (116 women and 22 men, with a mean age of $64.82 \pm 10.51$ years and between 43 and 81 years) were available at the time of the ebd of the study. Written informed consent for participation was obtained from each patient. Ninety-seven patients received alendronate, 19 risedronate, 7 zolendronate, and 15 ibandronate. At baseline, 13 patients had a prevalent vertebral, and 59 a prevalent non-vertebral fracture, while 22 had multiple fractures (Table 1.)

The study protocol was approved by the Regional Research Ethics Committee of the Univeristy of Debrecen, Medical and Health Science Center.

\section{Study endpoints}

The primary endpoint of the study was the change of bone mineral density (BMD) values (and T-scores) during one year with appropriate combination therapy with a bisphosphonate, vitamin $\mathrm{D}_{3}$, and calcium.

\section{Implementation of the study}

At baseline, the patient's medical history was taken, and physical examination was performed. All subjects underwent bone densitometry of the lumbar spine $\left(\mathrm{L}_{1-4}\right.$ vertebrae) and of the left femoral neck with antero-posterior dual-energy $x$-ray absorptiometry (AP DEXA) scanning, as well as an $\mathrm{x}$-ray of the dorsal-lumbar spine. Laboratory screening comprised the following: erythrocyte sedimentation rate (ESR), C-reactive protein (CRP), complete blood count $(\mathrm{CBC})$, serum calcium and phosphate, blood urea nitrogen (BUN), creatinine, aspartate aminotransferase (AST), alanine aminotransferase (ALT), alkaline phosphatase, serum albumin, urinary calcium/creatinine ratio, thyroid stimulating hormone (TSH), intact parathyroid hormone (iPTH), osteocalcin, carboxy-terminal collagen crosslinks (CTX).

Serum PTH was measured using electrochemiluminescence immunoassay (Roche Diagnostics $\mathrm{GmbH}$, Mannheim, Germany), where the inter-assay $\mathrm{CV}$ was $<7 \%$. This assay employs a sandwich test principle in which a biotinylated monoclonal antibody reacts with the N-terminal fragment (1-37), and a monoclonal antibody labeled with a ruthinium complex reacts with the C-terminal fragment (38-84). The antibodies in this assay are reactive with epitopes in the amino acid regions 26-32 and 37-42.

We repeated the DEXA scan after a one-year (13.37 \pm 1.29 months) follow-up on the average, and recorded the number of incident bone fractures and cases of renal stone formation that had occurred during this period.

\section{Table 1 The baseline characteristics of the sudy} population

\begin{tabular}{ll}
\hline Number of patients & 138 \\
Women/men & $116 / 22$ \\
Mean age (years) & $64.82 \pm 10.51$ \\
Treatment & Alendronate:97 \\
& Risedronate: 19 \\
& Zolendronate: 7 \\
& Ibandronate:15 \\
\hline
\end{tabular}


The subjects received adequate bisphosphonate therapy with alendronate, risedronate, or ibandronate administered in combination with $6000 \mathrm{IU} /$ week vitamin $\mathrm{D}_{3}$, as well as $1000 \mathrm{mg} /$ day calcium during the follow-up period.

The patients' compliance was evaluated at the scheduled quarterly visit, and a more than $80 \%$ compliance was acceptable to continue the study.

\section{Statistical analysis}

We formed two subgroups based on the change in bone mineral density (BMD) values as a result of therapy. The group of responders included all those patients in whom BMD level decreased as compared to the baseline value; the rest of the patients formed the group of nonresponders. The definition of bone loss (non-responders) was made if the bone mineral density was decreased by more than $1 \%$ of the initial value, because the variation coefficient is less than $1 \%$ in the case of Lunar Prodigy DXA device, which was used in this study. The normality of the distribution of datasets was checked with KolmogorovSmirnov test. We compared data from two independent groups using Mann-Whitney test. A general linear model was used to identify the factors influencing the magnitude of the change in bone density of the spine and of the femoral neck. All statistical analyses were performed with version 19.0 of the IBM SPSS Statistics software package.

\section{Results}

On enrolment in the study, PTH levels were normal in 112 patients, while it elevated in 26 cases. Baseline BMD measured at the $\mathrm{L}_{1-4}$ vertebrae, and at the left femoral neck by AP DEXA scanning was $0.854 \pm 0.108 \mathrm{~g} / \mathrm{cm}^{2}$, and $0.768 \pm 0.115 \mathrm{~g} / \mathrm{cm}^{2}$, respectively.

After a follow-up period and appropriate therapy for over one year on average, bone density increased to $0.890 \pm 0.111 \mathrm{~g} / \mathrm{cm}^{2}$ at the lumbar spine, and to $0.773 \pm$ $0.111 \mathrm{~g} / \mathrm{cm}^{2}$ at the femoral neck. Thus, the mean increase in BMD was $0.036 \mathrm{~g} / \mathrm{cm}^{2}$ and $0.005 \mathrm{~g} / \mathrm{cm}^{2}$, respectively.

We found a statistically significant $(\mathrm{p}<0.0001)$ difference between the baseline PTH levels of patient subsets with declining or non-declining bone density (using either BMD or T-score as the basis for grouping). However, creating these subsets according to femoral bone density (based on either the BMD or the T-score), the difference between PTH values was no longer significant (Figure 1).

The general linear model showed a strong, significant $(\mathrm{p}<0.0001)$ relationship between baseline PTH levels and the relative change in lumbar BMD (Figure 2). A similar correlation could not be demonstrated for the femoral neck, other variables (such as age, gender, etc.), and the change in BMD ( $\mathrm{p}>0.05)$.

We determined the prognostically optimal threshold of baseline PTH level, which best differentiated the
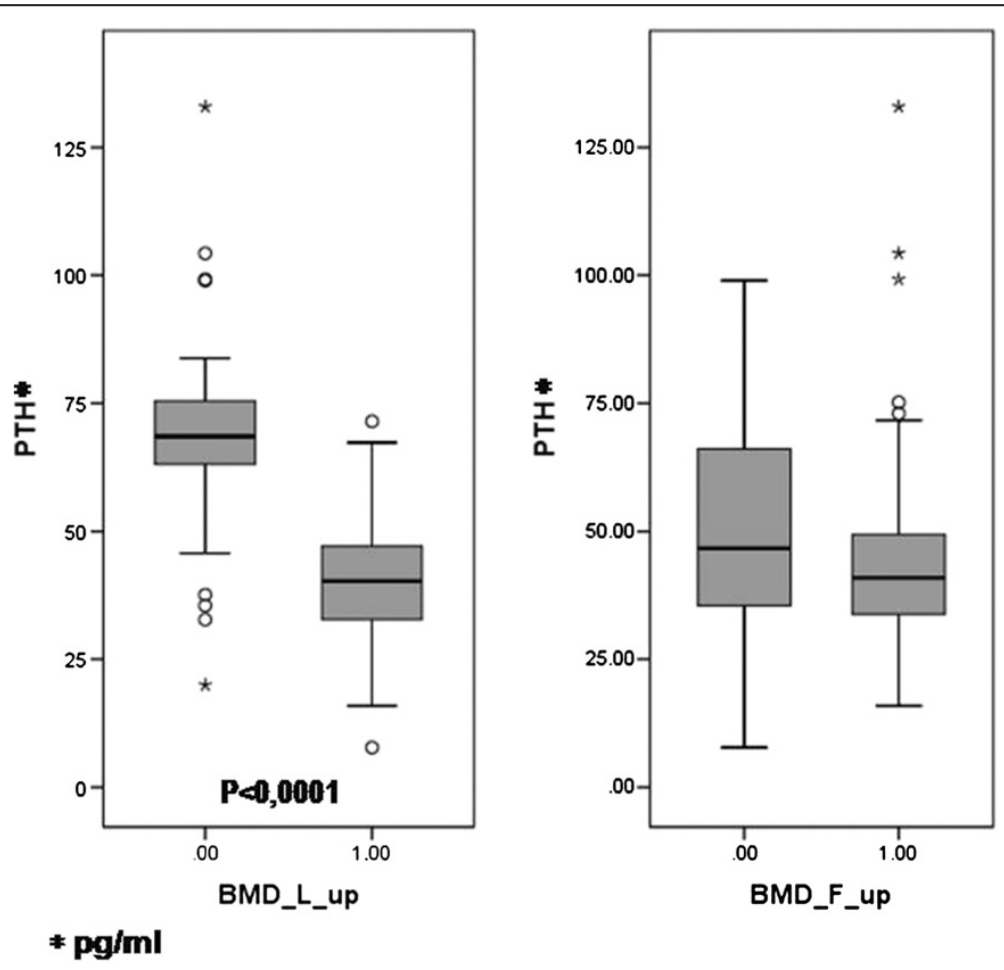

Figure 1 Baseline parathormone levels in the responder and non-responder subsets (0: declining bone mineral density/nonresponders/, 1: improving bone mineral density/responders/). 


\section{Rel_BMD_L}

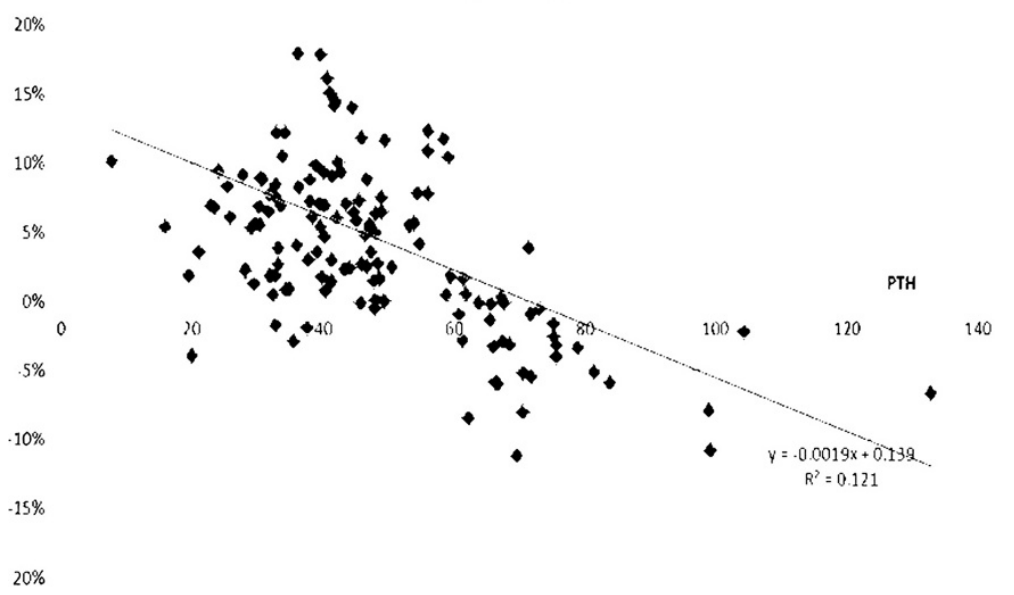

Figure 2 The relationship between baseline parathormone levels, and the changes in lumbar bone mineral density.

subsets with declining and improving lumbar BMD from each other. According to the frequency histogram (of PTH level plotted in units of $5 \mathrm{pg} / \mathrm{mL}$ ), this was at approximately $60 \mathrm{pg} / \mathrm{mL}$ for the lumbar spine (Figure 3 ). Regarding the femoral neck, the frequency histogram did not show any substantial difference between the subsets with improving or declining bone density.

New (incident) vertebral or non-vertebral fractures occurred in one and five subjects, respectively.

\section{Discussion}

Vitamin $\mathrm{D}_{3}$ deficiency and accompanying secondary hyperparathyroidism are extremely prevalent in the senior population of developed countries - regardless of geographical location or terrestrial latitude [17]. The weight of this problem is illustrated - among others by a survey conducted in Austria, the United Kingdom (UK), and Mexico. This study revealed that the proportion of patients receiving calcium and vitamin $D_{3}$ supplementation was $73 \%$ in Austria, $15 \%$ in the UK, and $12 \%$ in Mexico. Furthermore, only $20 \%$ of the patients in Austria were taking vitamin $\mathrm{D}_{3}-$ where the latter was provided free to osteoporotic patients $[18,19]$.

In $98 \%$ of patients hospitalized for non-traumatic fractures, $25(\mathrm{OH})$ vitamin $\mathrm{D}_{3}$ levels were found to be low, which was commonly associated with elevated PTH level

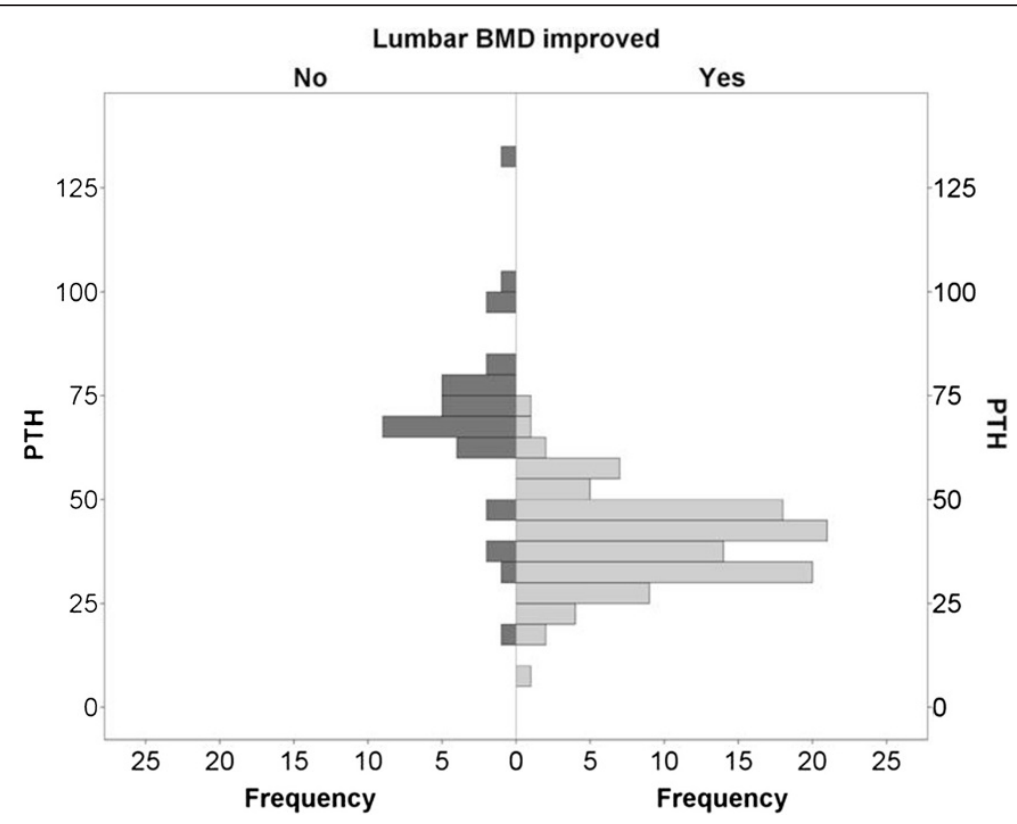

Figure 3 The frequency histogram of the parathormone levels in responders and non-responders. 
and hence, accelerated bone loss [20,21]. An inverse relationship has been shown between the risk of osteoporotic hip fractures and increased vitamin $\mathrm{D}_{3}$ intake, as well as greater adherence to supplementation [22].

There is an increasing number of reports suggesting that inadequate $(<30 \mathrm{ng} / \mathrm{mL})$ serum $25(\mathrm{OH})$ vitamin $\mathrm{D}_{3}$, and consecutively elevated PTH levels are among the essential factors behind bisphosphonate resistance, leading to unsatisfactory response to bisphosphonates $[15,16]$.

Previous studies have demonstrated that the increase of BMD in every skeletal region is greater in vitamin Dreplete patients than in those with vitamin D deficiency. Additionally, the risk of incident osteoporotic fractures is 1.77 times higher in the latter population, than in vitamin D-replete individuals [23].

Our findings confirm that elevated $(>60 \mathrm{pg} / \mathrm{mL})$ serum PTH levels exert an unfavourable influence on the efficacy of bisphosphonate therapy. We believe it would be important to determine PTH levels before bisphosphonate treatment is initiated. In particular, similar to a variety of other disorders, such as diabetes and hypertension, the success of anti-osteoporotic therapy is essentially dependent on a specific target PTH level $(<60 \mathrm{pg} / \mathrm{mL}$ in uor case). From an economic point of view, the cost of a single PTH measurement is far less than the annual expenditure on ineffective bisphosphonate therapy.

It is controversial whether administering an initial, oral loading dose of (40000 to $300000 \mathrm{IU}$ ) vitamin D is justified before initiating anti-resorptive therapy in hypovitaminosis $\mathrm{D}_{3}$. The administration of a single, $300000-\mathrm{IU}$ dose of vitamin $D_{3}$ could successfully normalize the serum $25(\mathrm{OH})$ vitamin $\mathrm{D}_{3}$ levels of patients within three months, without major adverse effects [24]. Regarding the $30 \mathrm{ng} / \mathrm{mL}$ (75 nmol/L) serum $25(\mathrm{OH})$ vitamin $\mathrm{D}_{3}$ concentration as the target level, others have provided therapeutic recommendations on the single loading dose [25].

The fracture-reducing effect of daily supplementation with 800 to $1000 \mathrm{IU}$ oral vitamin $\mathrm{D}_{3}$ is evident. In direct contrast to this, others have observed an increase (compared to placebo) in the number of falls, and fractures among their elderly female patients treated with yearly oral mega-dose (500000 IU) of vitamin $\mathrm{D}_{3}$ [26].

Although the authors could not explain this finding, the need for reducing the excessively high baseline level of PTH has not been fully addressed in previous studies.

Serum PTH levels, the vitamin $\mathrm{D}_{3}$-replete state, and supplementation with vitamin $\mathrm{D}_{3}$ are of significant importance in osteology. It is highly probable that the higher ( $>60 \mathrm{pg} / \mathrm{mL}$ in our study) baseline PTH levels observed before the initiation of anti-osteoporotic treatment have a clear effect on the therapy outcome. Whether long-term oral vitamin D supplementation or the administration of a single high dose vitamin $\mathrm{D}_{3}$ treatment is justified can be determined by additional large-scale studies.

\section{Conclusion}

This is the first study indicating the connection between the treatment efficacy and the PTH levels in newly diagnosed osteoporotic patients. Moreover, we determined a potentially "harmful" cut-off value for PTH levels. Our results suggest that the PTH levels higher than $60 \mathrm{pg} / \mathrm{mL}$ have negative prognostic value for the efficacy of antiporotic treatment.

\section{Study limitations and strength}

The relatively low patient number and the short follow-up are the possible limitations of this study. The main strenght of the study is that this is the first study to determine a cut-off PTH value, which affect the success of the bisphosphonate treatment in patients with osteoporosis.

\section{Competing interest}

The authors declare that they have no competing interests.

\section{Authors' contributions}

GK participated in patient recruitment, data capture and in the design of the study. JV performed the statistical analysis. PS participated also in the recruitment of patients and in the organisation of the study. PS participated in the design of the study and helped in drafting the manuscript. PS participated in the patient recruitment and data acquisition. JG conceived of the study, and participated in its design and coordination. All authors read and approved the final manuscript.

\section{Acknowledgement}

The authors would like to thank Dr. Ben Thomas for the session: linguistic revision of the article.

\section{Author details}

${ }^{1}$ Department of Rheumatology, 'Kenézy Gyula' Hospital, Bartók Béla út 2-26, $\mathrm{H}$ - 4032, Debrecen, Hungary. ${ }^{2}$ Department of Nuclear Medicine, University of Debrecen, Medical \& Health Sciences Centre, Debrecen, Hungary.

${ }^{3}$ Department of Orthopedic Surgery, University of Budapest, Budapest, Hungary. ${ }^{4}$ Institute of Immunology, Rikshospitalet, Oslo University Hospital, Oslo, Norway.

Received: 8 May 2012 Accepted: 6 December 2012

Published: 10 December 2012

\section{References}

1. Lunt M, Felsenberg D, Adams J, Benevolenskaya L, Cannata J, Dequeker J, Dodenhof C, Falch JA, Johnell O, Khaw KT, Masaryk P, Pols H, Poor G, Reid D, Scheidt-Nave C, Weber K, Silman AJ, Reeve J: Population-based geographic variations in DXA bone density in Europe: the EVOS Study. European Vertebral Osteoporosis Osteoporos Int 1997, 7(3):175-189.

2. Poór G: Osteoporosis care in hungary. Bull World Health Organ 1999, 77(5):429-430

3. Benford HL, Frith JC, Auriola S, Mönkkönen J, Rogers MJ: Farnesol and geranylgeraniol prevent activation of caspases by aminobisphosphonates: biochemical evidence for two distinct pharmacological classes of bisphosphonate drugs. Mol Pharmacol 1999, 56(1):131-140.

4. Allain TJ, Dhesi J: Hypovitaminosis D in older adults. Gerontology 2003, 49(5):273-278

5. Lips $P$, Vitamin D: Deficiency and secondary hyperparathyroidism in the elderly: consequences for bone loss and fractures and therapeutic implications. Endocr Rev 2001, 22(4):477-501.

6. Rejnmark $L$, Vestergaard $P$, Brot $C$, Mosekilde $L$ : Increased fracture risk in normocalcemic postmenopausal women with high parathyroid hormone levels: a 16-year follow-up study. Calcif Tissue Int 2011, 88(3):238-425.

7. Pfeifer M, Begerow B, Minne HW: Vitamin D and muscle function. Osteoporos Int 2002, 13(3):187-194.

8. Houston DK, Cesari M, Ferrucci L, Cherubini A, Maggio D, Bartali B, Johnson MA, Schwartz GG, Kritchevsky SB: Association between vitamin D status 
and physical performance: the InCHIANTI study. J Gerontol A Biol Sci Med Sci 2007, 62(4):440-446.

9. Kremer R, Bolivar I, Goltzman D, Hendy GN: Influence of calcium and 1,25-dihydroxycholecalciferol on proliferation and proto-oncogene expression in primary cultures of bovine parathyroid cells. Endocrinology 1989, 125(2):935-941.

10. von Mühlen DG, Greendale GA, Garland CF, Wan L, Barrett-Connor E: Vitamin $\mathrm{D}$, parathyroid hormone levels and bone mineral density in community-dwelling older women: the rancho Bernardo study. Osteoporos Int 2005, 16(12):1721-1726.

11. Steingrimsdottir L, Gunnarsson O, Indridason OS, Franzson L, Sigurdsson G: Relationship between serum parathyroid hormone levels, vitamin $D$ sufficiency, and calcium intake. JAMA 2005, 294(18):2336-2341.

12. Chapuy MC, Preziosi P, Maamer M, Arnaud S, Galan P, Hercberg S, Meunier PJ: Prevalence of vitamin $D$ insufficiency in an adult normal population. Osteoporos Int 1997, 7(5):439-443.

13. Bhattoa HP, Bettembuk P, Ganacharya S, Balogh A: Prevalence and seasonal variation of hypovitaminosis $D$ and its relationship to bone metabolism in community dwelling postmenopausal Hungarian women. Osteoporos Int 2004, 15(6):447-451.

14. Sebba Al: Significance of a decline in bone mineral density while receiving oral bisphosphonate treatment. Clin Ther 2008, 30(3):443-452.

15. Barone A, Giusti A, Pioli G, Girasole G, Razzano M, Pizzonia M, Palummeri E, Bianchi G: Secondary hyperparathyroidism Due to hypovitaminosis D affects bone mineral density response to Alendronate in elderly women with osteoporosis: a randomized controlled trial. J Am Geriatr Soc 2007, 55(5):752-757.

16. Gaál J, Bender T, Varga J, Horváth I, Kiss J, Somogyi P, Surányi P: Overcoming resistance to bisphosphonates through the administration of alfacalcidol: results of a one-year, open follow-up study. Rheumatol Int 2009, 30(1):25-31.

17. Harris SS, Soteriades E, Coolidge JA, Mudgal S, Dawson-Hughes B: Vitamine $D$ insufficiency and hyperparathyroidism in a low income, multiracial, elderly population. J Clin Endocrinol Metab 2000, 85(11):4125-4130.

18. Resch H, Walliser J, Phillips S, Wehren LE, Sen SS: Physician and patient perceptions on the use of vitamin $D$ and calcium in osteoporosis treatment: a European and Latin American perspective. Curr Med Res Opin 2007, 23(6):1227-1237.

19. Castelo-Branco C, Cortés X, Ferrer M, UNICAD study investigators: Treatment persistence and compliance with a combination of calcium and vitamin D. Climacteric 2010, 13(6):578-584.

20. Gallacher SJ, McQuillian C, Harkness M, Finlay F, Gallagher AP, Dixon T: Prevalence of vitamin $D$ inadequacy in Scottish adults with nonvertebral fragility fractures. Curr Med Res Opin 2005, 21:1355-1361.

21. Heaney RP: Vitamin D: how much do we need, and how much is too much? Osteoporos Int 2000, 11:553-555.

22. Deane A, Constancio L, Fogelman I, Hampson G: The impact of vitamin D status on changes in bone mineral density during treatment with bisphosphonates and after discontinuation following long-term use in post-menopausal osteoporosis. BMC Musculoskelet Disord 2007, 10(8):3. doi:10.1186/1471-2474-8-3.

23. Adami S, Giannini S, Bianchi G, Sinigaglia L, Di Munno O, Fiore CE, Minisola S, Rossini M: Vitamin D status and response to treatment in post-menopausal osteoporosis. Osteoporosis Int 2009, 20(2):239-244.

24. von Restorff C, Bischoff-Ferrari HA, Theiler R: High-dose oral vitamin D3 supplementation in rheumatology patients with severe vitamin D3 deficiency. Bone 2009, 45(4):747-749.

25. van Groningen L, Opdenoordt S, van Sorge A, Telting D, Giesen A, de Boer $H$ : Cholecalciferol loading dose guideline for vitamin D-deficient adults. Eur J Endocrinol 2010, 162(4):805-811.

26. Sanders KM, Stuart AL, Williamson EJ, Simpson JA, Kotowicz MA, Young D, Nicholson GC: Annual high-dose oral vitamin D and falls and fractures in older women: a randomized controlled trial. JAMA 2010, 303(18):1815-1822.

doi:10.1186/1471-2474-13-244

Cite this article as: Kincse et al:: The impact of secondary

hyperparathyroidism on the efficacy of antiresorptive therapy. $B M C$

Musculoskeletal Disorders 2012 13:244.

\section{Submit your next manuscript to BioMed Central and take full advantage of:}

- Convenient online submission

- Thorough peer review

- No space constraints or color figure charges

- Immediate publication on acceptance

- Inclusion in PubMed, CAS, Scopus and Google Scholar

- Research which is freely available for redistribution 